\title{
LOS ESTEREOTIPOS DEL HOMBRE Y DE LA MUJER EN UNA NOVELA PUBLICADA EN 1622: EL ANDRÓGINO, DE FRANCISCO DE LUGO Y DÁVILA
}

La relación entre los estereotipos culturales y la construcción de la identidad es un hecho frecuente ${ }^{1}$. En efecto, toda construcción, toda elaboración de una identidad, busca a menudo sus fundamentos, sus bases en conceptos que se nutren de la noción de estereotipo.

Esta dialéctica entre el estereotipo y la elaboración de la identidad no es siempre obligatoria. Sin embargo está presente de manera clara y distinta en la representación literaria de un fenómeno cualquiera. Es que la literatura no puede hacer más que simplificar la realidad para traducirla en signos. Y el estereotipo se relaciona con el lugar común, con el cliché, con la simplificación.

Ciertos géneros literarios se prestan más que otros a esta corriente estereotipada. Autores como Cervantes, creador español de la novela corta en el siglo XVII, tratan de alejarse de una novela a la italiana creada en España en la cual las situaciones y los personajes tienden a repetirse inexorablemente ${ }^{2}$. Pero el éxito cervantino tendrá consecuencias nefastas para la novela ya que los escritores postcervantinos van a tender a reproducir una fórmula afortunada sin tomar conciencia de la complejidad de la obra del ingenio de Alcalá. Por eso la novela corta postcervantina constituye un vivero de personajes y situaciones estereotipados.

${ }^{1}$ Un primer esbozo de este trabajo fue presentado en un seminario del CIREMIA en Tours, el 19 de marzo de 2005. En ese seminario se evocaba la problemática de los estereotipos culturales y de la elaboración de la identidad. Las sugerencias de los miembros presentes en las diferentes sesiones de ese seminario, en particular la reflexión de Jean-René Aymes sobre la noción de estereotipo, me han ayudado a modificar ese trabajo inicial y transformarlo en el que ahora presento.

${ }^{2}$ Cervantes se aleja del estereotipo y tiende a presentarnos personajes complejos y, en este sentido, absolutamente modernos. RUTH Fine ha estudiado este aspecto de la obra cervantina y dice: “...muchos de estos personajes [el morisco, el turco, el renegado, el judío...] rehuyen una posible lectura estereotipada o aún tipificadora y sus constituyentes acusan un juego permanente de estructuración/desestabilización, resistiendo así la reducción estereotípica" ("Reflexiones sobre la función del estereotipo en la obra cervantina”, en $C H[14]$, p. 227).

NRFH, LVI (2008), núm. 1, 155-173

56-1 NRFH 1-296.indd 155

3/3/08 8:53:43 PM 
Hay que reconocer también que los editores presionan en esta dirección. Citemos como ejemplo el caso de los Giunti o Giunta, editores e impresores presentes en diferentes países de Europa. Lanzan en 1620 la edición de las Doze novelas morales... de Diego Ágreda y Vargas. La colección aparece en tres ciudades peninsulares en este mismo año: Madrid, Barcelona y Valencia. Por otra parte, la edición francesa de 1621 se titula Nouvelles morales en suite de: celles de Cervantès ${ }^{3}$. Vemos muy claramente en la estructura de esta colección el deseo de reproducir un esquema de éxito asegurado: doce novelas, como en el caso de las Novelas ejemplares de Cervantes, un título similar (...novelas morales...) y, en el caso de la edición francesa, una atribución mentirosa (“...en suite de celles de Cervantès...”). Con respecto a los relatos también encontramos allí características que nos hacen pensar en la novela cervantina, pero extremadamente simplificadas ${ }^{4}$.

Esta corriente hacia el estereotipo habrá que situarla en un contexto cultural que José Antonio Maravall describe de manera explícita:

...tendremos que aceptar que, alrededor de las grandes obras que algunos hombres fueron capaces de crear en el siglo XVII, creciera por todas partes una cosecha de midcult y de mascult, cuyos productos van a ser empleados en la manipulación de esas masas de individuos sin personalidad, recortados en sus gustos y en sus posibilidades de disfrute, pero incapaces de renunciar a una opinión, aunque ésta no fuera más que una opinión recibida. Esas masas son el público... Lo que en el Barroco hay de kitsch es lo que en el Barroco hay de técnica de manipulación...5.

Es en este yacimiento rico de la novela corta española del siglo XVII, género literario que se desarrolla en un contexto de manipulación social, de simplificación y de kitsch, donde voy a encontrar un texto, un relato titulado El andrógino. ¿Por qué me intereso por este texto? Simplemente porque la problemática sexual planteada por la historia me parece un buen punto de partida para el estudio del estereotipo. La noción de estereotipo se construye a menudo a partir de la antítesis, y nada hay más antitético, al menos en un primer momento, que la distinción masculino-femenino.

Al hablar de la noción de novela familiar de los neuróticos, concepto evocado por Freud en un trabajo publicado en 1909, que sirve de

\footnotetext{
${ }^{3}$ Cf. estos datos así como también una bibliografía que permite profundizar la cuestión en mi artículo "Entre l'appartenance et l'exclusion. Reflexion sur les notions d'espace et de frontière à partir d'une lecture de La desgraciada amistad de Juan Pérez de Montalbán" (en prensa).

${ }^{4}$ Sobre esta colección de relatos véase el estudio de María Soledad ArRedondo, "Novela corta, ejemplar y moral: las Novelas morales de Ágreda y Vargas", Criticón, 1989, núm. 46, 77-94.

${ }^{5}$ La cultura del Barroco, $3^{\text {a }}$ ed., Ariel, Barcelona, 1983, p. 196.
} 
base a Marthe Robert para elaborar su teoría de la novela, la crítica francesa dice:

Le roman proprement dit commence à cette opposition qui, dans la mesure même où elle se fonde sur la différence des sexes et toutes les distinctions dont le sexe est le modèle, lui ouvre les mille perspectives de l'aventure, de l'intrigue, du conflit, bref tout un avenir d'action dans lequel il va pouvoir préciser ses desseins, sans renoncer pour autant à ses ambiguïtés ${ }^{6}$.

Estas reflexiones sobre la novela no pueden más que incitarnos a mirar la novela corta -que comparte con la novela la categoría de relato- desde una perspectiva similar. Estos conceptos bien diferenciados de lo femenino, próximo y trivial, y de lo masculino, lejano y noble, según el análisis de M. Robert (ibid., p. 50), están absolutamente presentes en la novela corta del siglo xvir. Pero el caso de El andrógino, por la temática misma del relato, plantea el problema de la frontera entre estas dos nociones y lleva al narrador a buscar ciertas caracterizaciones en un contexto ambiguo. La manera en que estas caracterizaciones son evocadas va a permitirnos sondear las imágenes de lo masculino y de lo femenino, tal como ellas son transmitidas por un género relativamente popular (en el sentido de su recepción y no de su producción).

El andrógino es una novelita de unas sesenta páginas que forma parte de una colección de Francisco de Lugo y Dávila titulada Teatro popular: novelas morales para mostrar los géneros de vidas del pueblo, y afectos, costumbres, y pasiones del ánimo, con aprovechamiento para todas personas ${ }^{7}$. En la portada comprobamos, como siempre, que algunas palabras están destacadas a través del formato tipográfico ${ }^{8}$. En efecto, se acentúan los términos teatro y popular así como también la expresión novelas morales que recuerda el título cervantino y todavía más la fórmula ya evocada de Diego Ágreda y Vargas ${ }^{9}$. La palabra teatro remite a las

${ }^{6}$ Roman des origines et origines du roman, Gallimard, Paris, 2004 [1972], pp. 50-51; las cursivas son mías.

${ }^{7}$ Consulto la edición príncipe en la Bibliothèque Nationale de France: FranCisco de Lugo y DÁvila, Teatro popular..., Viuda de Fernando Correa Montenegro, Madrid, 1622 [BNF: Rés Y2 3199]. Consulto también el ejemplar que se encuentra en la biblioteca del Centre d'Études Supérieures de la Renaissance en Tours [Res-C SR $16 \mathrm{~B}]$, cuya portada está incompleta.

${ }^{8} \mathrm{El}$ análisis de la portada no puede, en ningún caso, llevarnos a conclusiones con respecto al autor, ya que es, en principio, el resultado del trabajo del editor. Pero el análisis de la portada muestra la convergencia del trabajo de varios creadores y da del libro la imagen más aparente, la que transmite el primer mensaje. La portada de Teatro popular... ha sido reproducida por BEGOÑA RIPOLL en su libro La novela barroca. Catálogo bio-bibliográfico (1620-1700), Universidad, Salamanca, 1991, p. 106.

${ }_{9} \mathrm{El}$ paso del vocablo ambiguo y rico en significados, ejemplar, a la palabra más estandarizada y menos problemática, moral, es elocuente. Remito a un análisis más matizado de esta cuestión en el trabajo ya citado de M. S. Arredondo, "Novela corta, ejemplar y moral...". 
relaciones evidentes entre novela y comedia ${ }^{10}$ y ubica a nuestro género literario en una atmósfera de simulaciones y disfraces propia de ese mundo-espectáculo del barroco. Y si la tipografía resalta el término popular es ciertamente para acentuar el aspecto variado y múltiple del universo representado.

El libro de Lugo aparece en 1622 en Madrid, corte y ciudad cultural por excelencia, "a costa de Alonso Pérez", ese librero que domina el mercado del libro en ese momento, amigo y editor de Lope de Vega, padre de otro gran escritor de novelas cortas, Juan Pérez de Montalbán ${ }^{11}$. La redacción de Teatro popular estaba ya terminada en 1620, fecha de algunos textos preliminares como la aprobación de fray Alonso Remón fechada en Madrid en octubre de ese año ${ }^{12}$. Sabemos que Francisco de Lugo y Dávila fue nombrado gobernador de Chiapas en la Nueva España en 1621. Se había marchado de Castilla mucho antes de la publicación de su libro, como lo explica su hermano Dionisio Dávila y Lugo en el prólogo que agrega al del autor mismo ${ }^{13}$. Los textos preliminares muestran también que Lugo está bien integrado en el mundo literario madrileño: Juan Pérez de Montalbán y Alonso Jerónimo de Salas Barbadillo elogian la prosa del autor. Por su parte, Lugo y Dávila había redactado el prólogo alógrafo de Corrección de vicios, colección de novelas de Salas Barbadillo publicada en $1615^{14}$. Todo

${ }^{10}$ Véase al respecto el artículo de Florence Yudin, "The novela corta as comedia, Lope's Las fortunas de Diana", BHS, 45 (1968), 181-188. El término teatro tiene una significación muy amplia en el siglo XVIII e incluso antes, como dice JEAN JACQUOT: “...la comparaison de l'homme à un acteur et du monde à un théâtre est un lieu común de l'humanisme..." ("Le théâtre du monde de Shakespeare à Calderón", $R L C, 31$, 1957, p. 341). Esta interpretación, que sin duda Lugo también hace suya, enriquece y no excluye el sentido dramático que quiero atribuirle aquí al vocablo teatro. Sobre el mundo como teatro véase una buena síntesis en el artículo reciente de CHRISTIAN ANDRÈs, "La metáfora del théatrum mundi en Pierre Boaistuau y Calderón (en La vida es sueño y El gran teatro del mundo)", Criticón, 2004, núm. 91, 67-78.

11 Sobre Alonso Pérez, librero-editor en Madrid, véase el excelente estudio de Anne Cayuela, Alonso Pérez de Montalbán. Un librero en el Madrid de los Austrias, Calambur, Madrid, 2005.

${ }^{12}$ F. De Lugo y DÁvila, Teatro popular..., f. 2v, s/f.

13 Sobre los datos biográficos de Lugo y Dávila véase B. Ripoll, La novela barroca..., pp. 105-107 así como también la bibliografía que cita. Dionisio DÁvila y Lugo dice de su hermano: "Fin de ocupar muchas horas de la soledad de una aldea, donde asistía el autor deste libro, fue el principio de escribirle, no ambición de darle a la estampa: obligaciones forzosas le sacaron de España, dejándole en mis manos, no tan castigado y corregido como él quisiera..." (Teatro popular..., f. 9r; modernizo la ortografía y la puntuación)

14 Alonso Jerónimo de Salas Barbadillo, Corrección de vicios..., Juan de la Cuesta, Madrid, 1615 [B. N. F. R 50018], f. 3, s/f. Por otra parte, el caso de un hombre disfrazado de mujer (episodio poco frecuente en la novela corta española) está presente en una de estas novelas, Las narices del buscavidas: "Pues Céspedes se muda y se transforma / ...Sabréis el modo, no para imitarle / ...El bozo, que aun apenas le nacía, / Y el poco vello que la cara cubre, / Con la navaja quita sutilmente, / Dejando el rostro 
esto muestra una red de alianzas y de amistades propia del mundo literario de la época. A pesar de la ausencia de Lugo y Dávila, su libro se publica en Madrid y sigue su camino bajo la protección de todos estos personajes.

El origen noble del autor, la jerarquía de sus funciones en América y la lejanía explican un contexto de libertad evidente al publicarse su Teatro popular. Esa revisión de último momento, esa verificación del acuerdo entre el mundo representado en las novelitas y el proyecto de la ideología dominante, esa prudencia del creador en una sociedad bajo control están relativamente ausentes en el producto final del libro de Lugo. Éste es evidentemente el resultado de una primera redacción y en este sentido debemos apreciarlo como un texto muy significativo. Pero eso no quita que el libro se relacione con un proyecto comercial muy concreto en el cual se tiene en cuenta el horizonte de expectativa del público: con respecto a los personajes cada vez más convencionales y con respecto a las situaciones cada vez más triviales. El desafío del autor parece haber sido crear algo nuevo sin alejarse demasiado de lo ya existente.

La novela corta que vamos a analizar ha suscitado algunos estudios críticos en gran parte porque una de las fuentes de El andrógino es un relato de Cervantes, El celoso extremeño $0^{15}$. Estos trabajos se interesan más por aspectos comparativos y descuidan el relato de Lugo y Dávila como creación independiente e individual. Un estudio más reciente, el de Carmen Rabell, Rewriting the Italian novella in CounterReformation Spain ${ }^{16}$, explora otras vertientes de El andrógino, sin olvidar las relaciones que existen entre el texto de Lugo y el de Cervantes. Carmen Rabell se interesa por los lazos que existen entre la novela corta española y un tipo de discurso legal donde la controversia está muy presente. La problemática del casamiento provoca a menudo este tipo de controversia que la novela recrea. Eso permite oponer los puntos de vista de los hombres y de las mujeres por medio de debates que van a desbordar el marco de la narración para instalarse en la realidad de los lectores fuera del libro. Ahora bien, en este tipo de controversia veremos oponerse el discurso jurídico y el discurso canónico, el discurso masculino y el discurso femenino. En el caso particular presentado en El andrógino la ambigüedad sexual del personaje

limpio y liso, / ...Cualquiera de mujer le dará nombre, / ...También el traje, y ropas femeniles / Sobre sus torpes miembros acomoda..." (ibid., ff. 92-93; modernizo la ortografía). El episodio de Salas habría podido sugerir algunas ideas a Lugo, aunque Las narices del buscavidas va por camino diferente del que sigue El andrógino.

${ }^{15}$ Cf. Alberto Sánchez, "De las novelas ejemplares de Cervantes a las novelas morales de Lugo y Dávila”, ACerv, 20 (1982), 135-151; EdGARD NAGY, “Teatro popular” de Francisco de Lugo y Dávila y la ejemplaridad novelística de Cervantes, S. Cuesta, Valladolid, 1983.

16 Tamesis, London, 2003, pp. 140-152. 
va a permitir yuxtaponer estos discursos "femenino" y "masculino" creando relaciones singulares.

La antítesis masculino-femenino estaba ya muy presente en la novelita de Cervantes, El celoso extremeño. El viejo Carrizales, extremeño extremado, indiano rico, vuelve a Sevilla donde se enamora de una muchacha. Decide casarse a pesar de sus enfermizos celos. Para luchar contra este sentimiento y evitar el riesgo de verse engañado por su mujer, hace construir una casa fortaleza en la que todo lleva el signo de lo femenino:

[Carrizales]...no consintió que dentro de su casa hubiese algún animal que fuese varón. A los ratones de ella jamás los persiguió gato, ni en ella se oyó ladrido de perro; todos eran de género femenino... Jamás entró hombre de la puerta adentro del patio... Las figuras de los paños que sus salas y cuadras adornaban, todas eran hembras, flores y boscajes... No se vio monasterio tan cerrado, ni monjas tan recogidas, ni manzanas de oro tan guardadas... ${ }^{17}$.

Leonora, la joven esposa de Carrizales, va a ser encerrada en este "monasterio". La mujer aparece entonces asociada a este mundo interior, lo que remite a los lugares comunes que aparecen en los refranes: "La mujer en casa y el hombre en la plaza", "La mujer en casa y el hombre en la arada", "La mujer en casa, y la pierna quebrada"18. El verdadero mundo, amplio y abierto, sin fronteras, es el de los hombres que poseen además la llave de los mundos cerrados. Por otra parte, la llave, ese objeto real y simbólico, está muy presente en El celoso extremeño ${ }^{19}$. Ya no es necesario explicar la significación a la vez masculina y erótica de la llave. Citemos como ejemplo este villancico áureo:

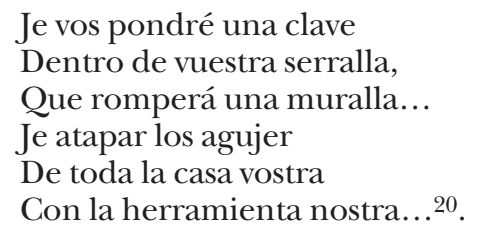

Hay allí una simbología evidente que también aparece en la novelita cervantina: la casa, las murallas, los agujeros, la llave...

Pero la frontera entre esos dos mundos masculino y femenino está también representada en el relato del escritor de Alcalá. En efecto,

17 Miguel de Cervantes, Novelas ejemplares, ed. H. Sieber, Cátedra, Madrid, 2002, t. 2, p. 106.

18 Gonzalo Correas, Vocabulario de refranes y frases proverbiales..., Visor Libros, Madrid, 1992, p. 324 a.

${ }^{19}$ Cf. M. De Cervantes, Novelas ejemplares, ed. cit., t. 2, pp. 108, 121.

${ }^{20}$ Pierre Alzieu, Robert Jammes e Yvan Lissourgues, Poesía erótica del Siglo de Oro, Crítica, Barcelona, 1984, p. 145. Cf., también, p. 150. 
entre la casa y la calle, entre el adentro y el afuera, se encuentra un espacio intermedio, la casapuerta ${ }^{21}$, donde vive un personaje de ambigua sexualidad: el eunuco Luis (p. 104).

Es este aspecto ambivalente de la sexualidad lo que vamos a ver desarrollado en la novela corta del madrileño Lugo y Dávila. El autor de Teatro popularva a explorar las certidumbres y las ilusiones de la identidad sexual creando el personaje de Ricardo que, disfrazado de mujer, se transforma en Bernardina. Esta perspectiva en la intriga de El andrógino sigue la otra fuente del relato, la Novella seconda de la colección de Agnolo Firenzuola titulada Ragionamenti d'amore ${ }^{22}$. El libro de Firenzuola fue publicado en Venecia hacia 1541 por Giovanni Griffio ${ }^{23}$. Pero los Giunti, esos grandes editores de novelas, van a reimprimir la obra en 1548 en Florencia (ibid., pp. 36-37). Por otra parte, la colección de novelitas italiana será incluida en el Index de Parma en 1580 (p. 52). Pero la severidad de este Index no será seguida en España: el Index madrileño de Quiroga de 1583 no condena las Novelle de Firenzuola (p. 53).

Esta Novella seconda presenta a un viejo personaje que decide un día casarse con una muchacha que pertenece a una familia numerosa. Un joven romano, Fulvio, quien ve a la hermosa esposa, Lavinia, se enamora perdidamente de ella. Le aconsejan que se disfrace de mujer y se presente a la casa de Lavinia donde buscan una criada. Fulvio, transformado en Lucía, es contratado o, mejor dicho, contratada. A la joven Lavinia le encanta pasar el tiempo con su criada, le gusta abrazarla y hacerle caricias ${ }^{24}$. Sólo que durante estos toqueteos Lavinia descubre que Lucía tiene como una especie de pequeña serpiente adosada al cuerpo. Está completamente maravillada. Toca de nuevo, mira de cerca. Llega a la conclusión de que Lucía se ha vuelto un hombre: "Io so pur che poco fa tu eri fémina, e or ti veggio esser venuto maschio!" (id.). La muy ingenua Lavinia se atemoriza, pero Fulvio/Lucía le dice la verdad. Tal historia maravilla a Lavinia que llega a entender la intensidad del amor de Fulvio. A partir de entonces Fulvio será mujer durante el día y se transformará en hombre durante la noche, compartiendo la alcoba de Lavinia. Esto hubiera podido durar años y años, pero el viejo marido acaba por descubrir la identidad masculina de Lucía. El

${ }^{21}$ M. De Cervantes, Novelas ejemplares, t. 2, p. 103.

22 Agnolo Firenzuola es un escritor nacido en Florencia en 1493. El argumento de la Novella seconda es el siguiente: "Fulvio si innamora in Tigoli: entra in casa della sua innamorata in abito di donna: ella trovatolo maschio, si gode sí fatta ventura. E mentre d'accordo si vivono, il marito si accorge che Fulvio è maschio, e per le parole sue e d'un suo amico si crede che e' sia divenuto cosí in casa sua; e ritienlo in casa à medesimi servigi per fare i fanciulli maschi" (Le novelle, a cura di A. Serón, Bompiani, Milano, 1943, p. 17; la novelita, en las pp. 17-24).

${ }^{23}$ Cf. Jean-Michel Laspéras, La nouvelle en Espagne au Siècle d'Or, Éditions du Castillet, Perpignan, 1987, p. 46, n. 60.

${ }^{24}$ A. Firenzuola, Le novelle..., p. 19. 
descubrimiento ocurre de la siguiente manera: el anciano se siente muy atraído por la criada, a quien encuentra un día dormida. Aprovecha para levantarle la falda y descubre: “...quelle cose ch'egli non andava cercando" (p. 21). El amo pide entonces una explicación. Lucía expone los hechos: al llegar a casa de su amo era una mujer, luego le nació esa $\operatorname{cosa}^{25}$ y él/ella se sintió muy avergonzado/a. El viejo trata de descifrar el misterio, consulta a un médico, se va a Roma... Acaban por hacerle comprender que se trata de un milagro portador de buenos augurios. En efecto, esta metamorfosis anuncia el futuro nacimiento de hijos varones en casa del anciano. Y tal cosa ocurre puesto que Lavinia dará a luz un varón. Finalmente Fulvio/Lucía seguirá viviendo en casa de su amo, quien le estará enteramente agradecido.

Desenlace feliz y licencioso el de esta novelita de Firenzuola, que se caracteriza por un ritmo rápido y una ausencia total de erudición ${ }^{26}$. A partir de este cañamazo así como también del relato cervantino Lugo y Dávila va a bordar su propia novela corta.

La colección de relatos de Lugo describe un jardín donde tres amigos (Celio, Fabio y Montano) se reúnen para pasar momentos agradables ${ }^{27}$. En este marco idílico cada uno va a contar historias durante algunos días. Se trata de un marco narrativo tradicional que se había impuesto a partir del Decamerón de Boccaccio, sólo que Lugo, como otros escritores, prefiere evocar un auditorio exclusivamente masculino 28 .

El punto de partida de cada relato es una cita que uno de los interlocutores debe amplificar como en el caso de algunos ejercicios de retórica ${ }^{29}$. El andrógino es la séptima novelita de la colección, que cuenta con ocho relatos. Sabemos que todo autor ubicará en primera posición un texto cautivante; también que reflexionará profundamente en cuanto a la elección del último relato, el que tendrá a menudo un sentido concluyente. La penúltima posición estará reservada a un texto que quizá no tenga el mérito de ser concluyente y edificante, pero que permita atraer la atención del receptor para llevarlo hasta el final del volumen. Este es el caso de El andrógino, cuyo título no podía más que despertar la curiosidad del lector.

25 “...mi è nata questa cosa..." (ibid., p. 22).

${ }^{26} \mathrm{El}$ problema del hermafroditismo aparece apenas subrayado por algunas fuentes librescas (ibid., p. 24).

27 Teatro popular..., ff. 1v-2v.

${ }^{28}$ Sobre la presencia o la ausencia de la mujer en los marcos narrativos de las colecciones de novelitas véase mi artículo "La femme, inspiratrice et réceptrice de la nouvelle au XVII ${ }^{\mathrm{e}}$ siècle", en Images de la femme en Espagne aux XVI ${ }^{e}$ et XVII ${ }^{e}$ siècles. Des traditions aux renouvellements et à l'émergence d'images nouvelles, éd. A. Redondo, Publications de la Sorbonne- Presses de la Sorbonne Nouvelle, Paris, 1994, pp. 365-379.

${ }^{29}$ Consúltese al respecto, por ejemplo, el libro de Andrés Gallego Barnés, Juan Lorenzo Palmireno (1524-1579). Un humanista aragonés en el Studi General de Valencia, Institución "Fernando el Católico", Zaragoza, 1982, pp. 120-124. 
Pero hay que precisar que El andrógino no es un título: se trata de un título interior ${ }^{30}$. Como dice Gérard Genette, el título interior se dirige a un destinatario que ya se ha introducido en la lectura de un texto (ibid., p. 271). Me gustaría revisar esta apreciación en el contexto del libro en la época clásica.

Estamos en un período en el cual el acceso al título general de una obra está mucho más restringido que hoy. No hay periódicos literarios, no hay publicidad y todavía menos emisiones radiofónicas. El libro no tiene cubierta. Seguramente se expone en la mesa del librero mostrando su portada. Es evidente que el cliente va más allá, hojea el libro, vuelve las páginas, se interesa por el prólogo que presenta la obra, mira el índice ${ }^{31}$. Y por lo que hace a nuestro Teatro popular..., el índice o tabla se encuentra en el principio mismo del libro, justo después de los textos preliminares, en la página 1 , primera página numerada.

No hay en esta época, sin carteles y sin periódicos, una distancia enorme entre la posibilidad de tener acceso al título y la de tener acceso al título interno. El cliente que recorre la tabla del Teatro popular... va a encontrar una primera novelita cuyo título tiene un carácter fuertemente moralizador: Escarmentar en cabeza ajena. Ocurrirá lo mismo en el caso del segundo título interior: Premiado el amor constante. Luego, Lugo elige títulos de carácter temático: Las dos hermanas, La hermanía, Cada uno hace como quien es, Del médico de Cádiz, Del andrógino, De la juventud. Hay que reconocer que entre estos títulos internos, el de El andrógino era el que más posibilidades tenía de intrigar y atraer al público ${ }^{32}$. ¿Por qué?

La problemática del ser andrógino estaba muy presente desde la antigüedad. La literatura se inspiraba en mitos y leyendas muy antiguas. En este sentido, los versos de Ausonio que sirven de inspiración a nuestra novelita y que el personaje de Celio propone a sus interlo-

30 Cf. GÉrard Genette, Seuils, Éds. du Seuil, Paris, 1987. En particular, "Les titres" (pp. 54-97) y "Les intertitres" (pp. 271-292).

31 Cf. el trabajo de Jaime Mold, "El libro, entorno del texto", en Le livre et l'édition dans le monde hispanique. XVI ${ }^{e}$-XVII ${ }^{e}$ siècles. Pratiques et discours paratextuels, études reúnes et présentées par M. Moner et M. Lafon, Université Stendhal-Grenoble III, Grenoble, 1992, en particular, pp. 12-13.

${ }^{32}$ MARIA ZERARI ha señalado ya el carácter audaz de este título interior, audacia que no es muy frecuente en la novela corta española (Du personaje féminin dans la nouvelle post-cervantine [1621-1663]. Contribution à l'étude de la nouvelle à travers le "personaje titre", Université de Paris III, Paris, 1998, pp. 174-175). La audacia de este relato es seguramente una de las causas que lleva a Nicolas Lancelot a adaptar el texto apenas algunos años más tarde para integrarlo en sus Nouvelles. La novelita de Lancelot se titula L'Hermaphrodite y se encuentra en la colección titulada Nouvelles, tirées des plus célèbres auteurs espagnols. Première partie, P. Billaine, Paris, 1628. Cf. José Manuel Losada Goya, Bibliographie critique de la littérature espagnole en France au XVII ${ }^{e}$ siècle. Présence et influence, Droz, Genève, 1999, pp. 254-255, 309-310. Un ejemplar de esta obra de Lancelot se encuentra en París en la Biblioteca del Arsenal [8-BL-29529]. 
cutores constituyen una buena síntesis. El epigrama latino se titula "Cambio de sexo" y lo cito en su traducción francesa:

À Villasana (nouvelle à peine croyable même pour des poètes, mais qui n'en vient pas moins d'une histoire véritable) un oiseau mâle prit la forme d'une femelle et un paon devint une paonne aux yeux de tous. Étonnement général devant ce prodige... Pourquoi cette sotte stupeur devant une nouveauté déjà connue? Ne lisez vous pas les vers d'Ovide? Consus, fils de Saturne, changea le sexe de Coenis; Tirésias eut successivement deux corps; la fontaine Salmacis vit le demi-homme Hermaphrodite; Pline a vu une mariée devenue androgyne. Il y a peu de temps, à Bénévent en Campanie une fille devint soudainement un éphèbe. Mais je ne veux pas rechercher des précédents dans une vieille tradition. Me voici, moi, qui, garçon, suis devenu femme ${ }^{33}$.

Este aspecto placentero de la transformación de sexo era particularmente divertido en el caso de Tiresias que había podido conocer, y así había podido comparar, los placeres de Venus en el caso de uno y otro sexo ${ }^{34}$. Estos pocos ejemplos muestran que la problemática del ser andrógino está relacionada también con la noción de metamorfosis ya que muy a menudo el hermafroditismo es el resultado de una mutación.

Pero el texto de Ausonio no se limita a dejar constancia de referencias míticas o literarias. El autor también alude a realidades cercanas, como la de la muchacha que en Campania se transformó en un efebo. Esta presencia concreta del hermafroditismo no faltaba en la España de Lugo.

Sabemos que la Inquisición de Toledo tuvo que enfrentarse en 1587 con el extraño caso de Elena o Eleno de Céspedes. En un estudio de Michèle Escamilla se hace una síntesis de la vida de este personaje:

Après les efforts de l'enfantement, Elena avait noté une étrange modification physiologique. Vers l'âge de vingt et un ans, elle eut sa première expérience sexuelle avec une femme... Elena, devenue tout aussi bien Eleno, entretient alors à l'insu du mari de coupables relations avec la belle Ana, seule partenaire qui connut, dit-elle, le mystère de sa sexualité35.

33 Ausone, Euvres en vers et en prose, trad. nouvelle M. Jasinski, Librairie Garnier Frères, Paris, 1935; t. 2, pp. 160-161. La novelita de LuGo incluye este epigrama en latín en la introducción del relato (Teatro popular..., f. 118r y v) y en castellano hacia el final de la historia (ibid., ff. 172v-173r).

34 Cf. Ovide, Les métamorphoses, trad., introd. et notes J. Chamonard, Flammarion, Paris, 1966, pp. 97-98 [Libro III].

35 Michèle Escamilla, "Á propos d'un dossier inquisitorial des environs de 1590: les étranges amours d'un hermaphrodite”, en Amours légitimes-amours illégitimes en Espagne (XVI ${ }^{e}-\mathrm{XVII}{ }^{e}$ siècles), éd. A. Redondo, Publications de la Sorbonne, Paris, 1985, p. 171. Cf. también el trabajo de Marie-Catherine Barbazza, "Un caso de subversión social: el proceso de Elena de Céspedes (1587-1589)", Criticón, 1984, núm. 26, 17-40. 
El caso de Elena de Céspedes lleva a que se hagan estudios médicos cuyas huellas se encuentran en el expediente inquisitorial.

Por otra parte, las relaciones de sucesos, esa prensa sensacionalista de la época, evocan casos de hermafroditismo. Antonia Morel d'Arleux escribió un trabajo apasionante sobre dos relaciones de sucesos de hermafroditas, una de las cuales es sólo unos años anterior a la fecha de la publicación de la novela de Lugo: "Relación verdadera de... un caso digno de ser avisado, como estuvo doce años una monja profesa, la que habría metido su padre por ser cerrada, y no ser para casada; y un día haciendo un ejercicio de fuerza se le rompió una tela por donde salió la naturaleza de hombre como lo demás, y lo que se hizo para sacarla del convento: ahora sucedido en este año de mil y seiscientos y diecisiete"36. Se trata del caso más frecuente, el de la mujer transformada en hombre. Los tratados de medicina evocan muchos ejemplos similares ${ }^{37}$.

No insistiré aquí sobre las relaciones existentes entre el género novela y la actualidad. El término mismo, novela, es polivalente en la época, como notamos al leer la definición de Covarrubias: "Novela. Nueva que viene de alguna parte, que comúnmente llamamos nuevas. 2. Novela, un cuento bien compuesto..." 38 .

Es evidente que Lugo y Dávila se inspira al mismo tiempo en una tradición literaria y en una actualidad sorprendente y extraordinaria al elegir el título de su novelita. Este título no puede más que llamar la atención del público.

Existen, con respecto al título, tres funciones posibles que Gérard Genette ha señalado: designación (única función obligatoria), indicación del contenido y seducción del público ${ }^{39}$. Veremos que estas tres funciones están presentes en El andrógino. Acabamos de probar que la tercera (seducción del público) es empleada con una fuerte intensidad en la medida en que la referencia al ser andrógino cautiva por su sorprendente audacia. Por lo que hace a la segunda función (indicación del contenido), Lugo se sirve de ella de modo relativamente engañador.

En efecto, una mirada rápida de la estructura de la novelita nos permite comprobar que el tema del hermafroditismo es en principio

36 Antonia Morel D’Arleux, "Las relaciones de hermafroditas: dos ejemplos diferentes de una misma manipulación ideológica", en Las "relaciones de sucesos" en España (1500-1750). Actas del Primer Congreso Internacional (Alcalá de Henares, 8,9 y 10 de junio de 1995), Publications de la Sorbonne-Servicio de Publicaciones de la Universidad de Alcalá, Paris, 1995, p. 264; modernizo la ortografía.

${ }^{37}$ Cf. ibid., pp. 262-263; M. Escamilla, "À propos d'un dossier...”, pp. 177-181; Elena del Río PARRa, Una era de monstruos. Representaciones de lo deforme en el Siglo de Oro español, Universidad de Navarra-Iberoamericana-Vervuert, Madrid-Frankfurt/M., 2003, pp. 86-100; РAtrick Graille, Les hermaphrodites aux XVII ${ }^{e}$ et XVII ${ }^{e}$ siècles, Les Belles Lettres, Paris, 2001.

${ }^{38}$ Sebastín de Covarrubias Orozco, Tesoro de la lengua castellana o española, ed. F. C. R. Maldonado, rev. por M. Camarero, Castalia, Madrid, 1995, p. 780 a.

${ }^{39}$ G. Genette, Seuils..., p. 73. 
secundario y subsidiario en la intriga. Veamos rápidamente los acontecimientos relatados en el texto.

A partir del epigrama de Ausonio, "Cambio de sexo", uno de los interlocutores se propone crear un relato. Éste comienza en Zaragoza, pero se desarrolla luego en Valencia. La joven Laura, noble, está enamorada desde su más tierna infancia de su vecino Ricardo, noble también y mucho más rico. Los padres de Ricardo se oponen al casamiento de su hijo con Laura. Deciden enviar a Ricardo a Valencia para proseguir allí sus estudios. Entretanto un viejo señor, Solier, que pertenece a la familia de Laura, llega a Zaragoza y pide la mano de la muchacha. A pesar de algún momento de vacilación, los padres de Laura aceptan finalmente casar a su hija con su tío Solier. Solier se marcha con su joven mujer a Valencia, donde vive ${ }^{40}$. La segunda parte de la novela se desarrolla en Valencia y nos interesa de manera más concreta ya que es allí donde se desarrolla el episodio de la metamorfosis sexual.

La casa de Solier en Valencia es una fortaleza de la que él es el único que posee la llave ${ }^{41}$. Por otro lado, para evitar que su mujer vaya a misa (la iglesia es frecuentemente un lugar de encuentro y en este sentido muy peligroso), Solier propone a un sacerdote, el licenciado Burgos, que celebre misa en su casa. Entretanto, Ricardo busca la manera de introducirse en la casa de Laura. El joven enamorado, disfrazado de mujer y adoptando el nombre de Bernardina, se hace proteger por Solier que le abre las puertas de su "monasterio". A partir de entonces Laura y Ricardo/Bernardina pueden disfrutar de los "bienes de amor"42. Pero el viejo Solier se enamora de Bernardina/Ricardo y decide un día entrar en su aposento mientras él/ella duerme. La escena es la siguiente:

...llegó a la cama de Ricardo, levantó la ropa alborozado y cuando imaginó hallar a doña Bernardina, halló diferente persona, viendo que la que tenía por mujer no lo era... [y entonces le dijo:] Dime quién eres antes que te quite la vida... ¡Ay de mí triste!, dijo Ricardo... ¡Oh pluguiera a

40 “...y con esto se efectuó matrimonio tan desemejante..." (Teatro popular..., f. 131v). No puedo explayarme aquí sobre la problemática del matrimonio, central en la primera parte de la novelita y en su desarrollo. Por otra parte, la introducción del relato evoca propósitos de tipo moral: "Enseña cuánto son dañosos los casamientos entre personas desiguales en edad: los riesgos que traen consigo, sin librar de los daños las prevenciones. Cómo los sabios, aunque se hallen en las dificultades salen bien d'ellas, descúbrense los afectos propios a las edades" (ibid., f. 118 r; modernizo siempre la ortografía al citar El andrógino).

41 "Las cerraduras de mi casa las he trazado de suerte que todas las pueda yo abrir y cerrar con una llave maestra, sin embargo que sean diferentes, y las llaves particulares no saldrán de mi escritorio, sino cuando yo quisiere...” (ibid., f. 130r).

42 “...por más de dos horas Ricardo y Laura seguros gozaron quietamente de los bienes de amor... [y todavía más] en casi veinte días que estuvo quieta la fortuna..." (ibid., f. 161r). 
Dios que primero de verme transformada de doncella en hombre hubiera el alma desamparado un tan triste cuerpo! ¿Luego mujer has sido? Dijo admirado Solier. Sí señor, respondió Ricardo, y mujer llegué a la quinta... habrá sólo tres días que se me fueron acrecentando las fuerzas y engrosando la voz... (ibid., f. 162r y v).

La descripción de la transformación de Bernardina provee ya elementos para el estudio del estereotipo masculino: la virilidad se encuentra en la fuerza física y en la voz grave. Pero preferiría describir antes el final de la intriga.

Ante la duda, Solier acepta consultar al licenciado Salt, catedrático de Medicina de la Universidad de Valencia. El erudito escucha a Solier y le pide que lo deje reflexionar un tiempo; su conclusión será expresada públicamente durante su clase de medicina ${ }^{43}$. Transcribo los momentos esenciales de la exposición del profesor Salt:

... no está oscura la razón de semejantes transformaciones, porque la mujer es casi monstruo y lo mismo que varón imperfecto, y como la naturaleza siempre desea lo que es mejor (como enseña Aristóteles...) perfeccionando con las partes de calor necesarias los cuerpos... muchas veces ha hecho naturaleza una hembra, y lo ha sido algunas veces en el vientre de su madre, y sobreviniendo copia de calor, queda hecho hombre: y que los tales se conocen después en ciertos movimientos que les quedan indecentes para varones, porque tienen la voz blanda y melosa... y por el contrario tiene hecho naturaleza un varón y sobreviniendo frialdad, queda hecho hembra, que después se conoce, porque las inclinaciones y acciones destas son varoniles... ${ }^{44}$.

El profesor Salt prosigue con su discurso aludiendo a las metamorfosis que ocurren a la edad adulta:

...la transformación que se hace de hembra en varón (que es cierta y ha sucedido muchas veces) lo que la causa es que por falta de calor, habiéndose formado las señales de hombre se están encogidas que no parecen; y después con la edad, aumentándose el calor y perfeccionándose, salen fuera y se manifiestan, quedando de hembra que antes era hecho varón perfecto... el mudarse de hembras en varones no es fabuloso... (ibid., f. $167 \mathrm{ryv}$ ).

Las citas antiguas y modernas son muy numerosas en la ponencia de Salt (de Plinio a Torquemada, de Tito Livio a Juan Fragoso). Me

${ }^{43}$ Verifico la no existencia de un profesor de medicina de este nombre en Valencia en los años anteriores a la redacción de la novelita de Lugo en el libro de Josế Teixidor y Trilles, Estudios de Valencia. (Historia de la Universidad hasta 1616), ed., introd., notas e índices L. Robles, Universidad, Valencia, 1976; se trata sin duda de un nombre inventado.

${ }^{44}$ Teatro popular..., f. $166 \mathrm{r}$ y v. 
gustaría subrayar la importancia de este último, médico de Felipe II y autor de una Cirugía universal editada varias veces, porque la conferencia de Salt es en parte un plagio del tratado de Juan Fragoso ${ }^{45}$.

Como ocurre a menudo en los libros donde se evocan tanto el hermafroditismo como otros fenómenos biológicos, se confunden fuentes literarias y fuentes científicas. Lo que es interesante es la abundancia de citas.

Este último caso evocado por Salt se acerca mucho al de Elena de Céspedes. Por otro lado, el ejemplo de la relación de sucesos de 1617 no está tampoco tan alejado. Podemos comprobar entonces que Lugo y Dávila elabora su historia de simulacros y engaños a partir de hechos totalmente verosímiles para la época.

Pero ¿cuál es la actitud del viejo Solier ante todas estas explicaciones eruditas? El profesor Salt, que estaba al corriente de la historia de Ricardo/Bernardina, da al final de su discurso una conclusión ambigua que podía despistar a quien lo deseara:

De todo lo cual concluyo que mudarse de hembra en varón es natural y verdadero; mudarse por el contrario, de varón en hembra, como de sí dice Ausonio: Yo de hembra en varón me he transformado. Es bernardina y fábula, y por tal la tenga todo hombre cuerdo. Con esto se bajó de la cátedra el Licenciado Salt, quedando Solier (que atentísimo había estado) satisfecho de que naturalmente se había vuelto Bernardina varón, sin reparar en las postreras palabras del Catedrático, donde agudamente le dijo la verdad.... ${ }^{46}$.

Estas postreras palabras deben ser entendidas en el contexto burlesco del relato. El término bernardina significa mentira, discurso vacío ${ }^{47}$.

45 Cito, para fundamentar lo que digo, algunos fragmentos: "También afirman algunos que muchas veces ha hecho naturaleza una hembra, y lo ha sido algunos meses en el vientre de su madre, y sobreviniendo a los miembros genitales copia de calor, salir afuera, y quedar hecho hombre: lo cual se conoce después en ciertos movimientos que tienen indecentes para varones, tienen la voz blanda y melosa, son inclinados a hacer obras mujeriles y caen en pecado nefando; y por el contrario, tiene muchas veces hecho un varón con sus genitales fuera y sobreviniendo frialdad se les vuelven adentro y queda hecha hembra. Conócense después en tener el aire y meneos de varón, así en la habla como en todos los movimientos y obras..." (JuAN FraGoso, Cirugía universal ahora nuevamente emendada y añadida en esta sexta impresión, Juan Gracián, Alcalá de Henares, 1621, f. 162v [B. N. P. : Fol Td ${ }^{73}$ 63]; modernizo la ortografía del texto citado). Este fragmento pertenece al capítulo titulado "Cuestión Quinta. Si es posible tornarse las mujeres en hombres?”. Los argumentos de Fragoso son muy similares a los evocados en otros tratados de la época. Cf., fundamentalmente, E. DEL Río PARra, Una era de monstruos... y P. Graille, Les hermaphrodites...; ninguno de ellos cita, sin embargo, el tratado de Fragoso.

46 Teatro popular..., f. $175 \mathrm{v}$.

47 Véase el artículo bernardina en la tesis de Monique Joly, La bourle et son interprétation. Recherches sur le pasaje de la facétie au roman. (Espagne. XVI ${ }^{e}$-XVII ${ }^{e}$ siècles), Atelier National de Reproduction des Thèses, Lille, 1982, pp. 138-142. 
La frase: "Es bernardina y fábula...", cuya puntuación no está muy clara, parece significar (y por otra parte el narrador lo confirma) que la historia de Bernardina no es más que una fábula, una ficción menti$\mathrm{rosa}^{48}$. Así, a pesar de los vastos conocimientos del profesor Salt, lo que hay que retener es muy simple: Bernardina, como su nombre lo indica, no es más que un engaño, una mentira. Pero Solier no ve el ardid, lo que permite que el relato termine de manera feliz. Cuento los acontecimientos muy rápidamente: Solier pide perdón a Bernardina, luego muere y Laura, que se vuelve rica, se casa con Ricardo.

Pero a lo largo de este episodio que compara las características del hombre y de la mujer nos enfrentamos con unas nociones estereotipadas que voy a intentar comentar.

Cuando Ricardo decide penetrar en la casa de Laura, la situación se evoca de la manera siguiente: “...hizo... que le hicieran vestido de mujer a su medida, y ensayándose algunas veces en el uso y ademanes..."49. Hay allí algunos elementos interesantes. Primero el vestido ("vestido de mujer"). El vestido y la falda han sido durante largo tiempo marcas de feminidad. La aparición del pantalón femenino suscitó debates en el siglo xx. Por otra parte, la falda masculina (fuera de ciertos atuendos regionales) está hoy relacionada con cierto discurso contestatario $^{50}$. Pero este vestido hay que saberlo llevar, hay que saber moverse con un estilo femenino. De allí lo del "ensayándose algunas veces" al que alude el narrador y que remite a esos "ciertos movimientos que les quedan indecentes para varones" de los que hablaba el profesor Salt (frase transcripta casi textualmente de un tratado médico, el de Fragoso). Hay, como el texto lo dice, "ademanes" propios de mujeres.

Toda una construcción identitaria está relacionada con el ademán. Hay ademanes de hombre y ademanes de mujer, como hay juegos de

48 Según S. de Covarrubias en su Tesoro...: "Fábula... Tómase también comúnmente fábula por cosa sin fundamento; y así decimos: Eso es fábula, que vale tanto como eso es mentira" (p. 531 b)

49 Teatro popular..., f. 145 r.

${ }^{50}$ Más allá de lo que el disfraz femenino puede significar en las gay pride comprobamos hoy que, por ejemplo, la danza integra la falda masculina con la función de valorizar los intercambios entre las identidades sexuales. Así, en los últimos espectáculos de la Compañía Nacional de Danza de España, dirigida por Nacho Duato, vemos a los bailarines dar pasos de danza en faldilla o en vestidos más sofisticados. Me resultaría imposible trazar la historia de esta actitud que se difunde cada vez más en escena. Sobre el mundo dividido en dos y las manifestaciones exteriores e interiores de esta dualidad remito a unas líneas de SimONE DE BEAUvorR: “...l'humanité se partage en deux catégories d'individus dont les vêtements, le visage, le corps, les sourires, la démarche, les intérêts, les occupations sont manifestement diferentes: peut-être ces différences sont-elles superficielles, peut-être sont-elles destinées à disparaître. Ce qui est certain c'est que pour l'instant elles existent avec une éclatante évidence" (Le deuxième sexe, Gallimard, Paris, 1981, t. 1, p. 13). Lugo presta mucha atención a estas diferencias culturales y no se limita a describirnos solamente una transformación biológica. 
varones y juegos de niñas. El personaje de Lugo se construye una nueva identidad y esa elaboración pasa primero por el ademán.

Luego Ricardo se atribuye otro nombre, Bernardina, en relación con una autobiografía ficticia de mujer que se inventa y que cuenta ${ }^{51}$. Este nombre femenino está también asociado, como lo hemos visto, a un discurso engañador e incluso carnavalesco. En efecto, este nombre es portador de una serie de inversiones: inversión de sexo, disfraz de la identidad, fórmula que permite pasar de un mundo exterior a un mundo interior y cerrado, etc..$^{52}$.

Más tarde, cuando el viejo Solier ve a Ricardo/Bernardina por primera vez, la puesta en escena es la siguiente:

[Ricardo]... decide ponerse a tocar el arpa en el jardín y cantar... y en este tiempo llegó Solier [...Cuando] ya habían tocado en sus oídos los acentos de las cuerdas y los ecos de la voz de Ricardo... Solier pudo ver a don Ricardo, sin ser visto, quedando atónito de tanta belleza....53.

La seducción de Solier (que va a permitir a Ricardo entrar en la casa del viejo) es primero de tipo musical. Como en el caso de las sirenas, seres monstruosos que atraen a los navegantes con la dulzura de su canto, nuestro andrógino va a seducir por medio de su voz. Esta voz es una voz femenina, sin duda "blanda" y "melosa", como afirman los tratados médicos citados en el texto ${ }^{54}$. Más adelante, Ricardo dirá que al transformarse en varón su voz se volvió más grave ${ }^{55}$.

51 Teatro popular..., ff. 147v-150v. La autobiografía de Bernardina comienza así: "En un lugar de Castilla la Vieja, que llaman Medina del Campo, nací y me crié...".

52 En todo relato en el que se trata el problema de la identidad, y más si se trata de la identidad sexual, el nombre se transforma en un símbolo esencial. Cito aquí un fragmento de la novela de NoËLle ChÂtelet, La tête en bas, que cuenta la historia de un hermafrodita: "Chaque jour de classe, je dois me déguiser, «Denise», m’accoutrer, chaque jour me travestir... Quant au nom de il m'est devenu si étranger que les professeurs doivent m'appeler plusieurs fois avant que je me rende compte que c'est à moi qu'on s'adresse" (Seuil, Paris, 2002, p. 48). Luego el personaje cambia de nombre y se llama Paul (p. 59). Sobre el nombre y la palabra, y sus características masculinas o femeninas cf. estas líneas de FRAY LUIS DE LEÓN, que me es imposible comentar en este trabajo, en su De los nombres de Cristo: “...Algunos, si lo que significan, por algún accidente, siendo varón, se ha afeminado y enmollecido, ellos también toman letras de las que en aquella lengua son, como si dijésemos, afeminadas y mujeriles. Otros, al revés, significan cosas femeninas de suyo, para dar a entender algún accidente viril, toman letras viriles" (ed. C. Cuevas García, Cátedra, Madrid, 1982, p. 163). Todo esto para significar hasta qué punto el nombre lleva consigo características sexuales o de género, y hasta qué punto los hombres del Siglo de Oro son conscientes de ello.

53 Teatro popular..., ff. $151 \mathrm{v}-152 \mathrm{v}$.

${ }^{54}$ Cf. las citas del discurso de Salt en la novela misma (ff. 166-167) y el discurso de Fragoso en su Cirugía universal (n. 55).

55 Teatro popular..., f. 162v. Con respecto al estereotipo de la voz femenina cito al personaje de la novela de NoËLle CHÂtelet, quien dice: "On ne peut pas être fille avec une voix qui ne claironne ni ne minaude dans les suraigus au point de vous 
Puesta en escena engañadora y teatral, disfraces y juegos del ser y del parecer, intriga barroca a medida del deseo. Y, sin embargo, en este encuentro entre Ricardo y Solier hay algo ambiguo. Este hombre que se deja seducir por otro hombre y se enamora de él representa un episodio equívoco de homosexualidad masculina. El motivo no es nuevo, pero quizá sea más evidente en el caso de un relato titulado $\mathrm{El}$ andrógino.

La mirada más reciente de los especialistas queer de literatura medieval abre nuevas perspectivas de trabajo a propósito de estas cuestiones. Según François Cusset, estos críticos:

Ils renforcent tous, de près ou de loin, l'hypothèse centrale qui est la sienne [la de la crítica queer] concernant la culture médiévale et ses raffinements français, l'hypothèse d'une inversion constante des rôles sexuels, d'une mobilité ostentatoire entre le féminin et le masculin qui constituerait un motif majeur de la littérature médiévale -où il n'est pas rare de voir des chevaliers se jurer entre eux un amour plus fidèle qu'à leur belle, et non sans attouchements, et les femmes se parer des atours du guerrier... ${ }^{56}$.

Esta temática, que la literatura española de los siglos XVI y XVII tampoco va a eludir, se nutre también en la realidad. Recorriendo, por ejemplo, los testimonios del padre Pedro de León (1545-1632) sobre la cárcel de Sevilla y sus prisioneros, encontramos personajes que nos hacen pensar en Ricardo (a pesar de que sus metas no sean las mismas). Citemos el caso de Francisco Galindo: “...hijo de un sedero de Málaga, que andaba con tantas galas y parecía más mujer que hombre, las cuales dicen que le daban los que usaban con él aquella desventura [el pecado nefando], porque siempre servía de mujer y era él el paciente..."57.

écorcher les oreilles" (La tête en bas..., p. 33). Sobre la voz femenina en un hombre hay al menos dos refranes: "Hombre hablimujeril, líbreme Dios de él" y "Hombre palabrimujer, guárdeme Dios de él” (G. DE Correas, Vocabulario..., p. 245 b). JuAN DE MAL LARA, que no cita el segundo en su Filosofía vulgar, provee una explicación extremadamente interesante: "Las mujeres tienen la voz muy aguda, y más que la de los hombres, porque, según dice Aristóteles, lib. 4, cap. último de la Historia de los animales, que la voz, en las hembras es más delgada, y más aguda, en todas las especies de los animales, sino en las vacas, que la tienen más gruesa que los toros... Pues siendo la voz grave del varón, y la delicada de la hembra, hallar otra cosa contraria es fuera de la orden de la naturaleza. Y habémonos de guardar de hombres a quienes oímos hablar como mujer, por alguna malicia secreta que hay en el que, no sin causa, anda señalado de la misma naturaleza..." (Obras completas, ed. y pról. M. Bernal Rodríguez, Biblioteca Castro, Madrid, 1996, t. 1, pp. 240-241).

${ }^{56}$ François Cusset, Queer critics. La littérature française déshabillée par ses homo-lecteurs, Presses Universitaires de France, Paris, 2002, p. 57.

57 Cf. Pedro Herrera Puga, Sociedad y delincuencia en el Siglo de Oro, pról. J. Cepeda Adán, $B A C$, Madrid, 1974, pp. 246-269, y el caso de F. GAlindo, pp. 249-250. Cf., también, BARTolomé BenASSAR, L'Inquisition espagnole (XV'-XIXe siècles), Marabout, Paris, 1983, pp. 330-358. 
En este universo de transexualidad y de libertinaje son a menudo los jóvenes los que, maquillados, se dejan arrastrar al pecado "abominable". Estas actividades tienen lugar en la ciudad, en las casas de juego, o fuera de ella, en las huertas y quintas donde la vegetación puede esconder los encuentros amorosos ${ }^{58}$. Según el padre León, la homosexualidad está presente en todas las jerarquías sociales. Está también relacionada con unas maneras particulares en el vestir y en los ademanes ${ }^{59}$.

Todo esto recuerda la escena donde el viejo Solier mira a un hombre joven disfrazado de mujer y se siente atraído por él. En esta novelita de las apariencias la movilidad entre lo masculino y lo femenino es constante, y quizá no solamente en el caso del personaje de Ricardo/Bernardina. Por eso el título El andrógino es seguramente menos engañador de lo que uno piensa. Ciertamente, Ricardo no es un verdadero hermafrodita. Tiene un solo sexo. Pero las fronteras entre la bisexualidad biológica y la bisexualidad psíquica no están siempre muy claras $^{60}$. Por otra parte, a la literatura de ficción le agrada confundirnos y despistarnos para ampliar nuestra sorpresa.

Si los estereotipos masculinos y femeninos están allí, en el relato de Lugo, es también para provocar escenas carnavalescas en las cuales el hombre y la mujer se vuelven un ser único, capaz de metamorfosearse según la necesidad. Si Ricardo se vuelve mujer para visitar a su amada, no deja de volver a ser hombre cuando le toca compartir el lecho con Laura. Pero quizás a Laura le resulte placentera esta aventura en la que le toca en suerte hacer como que acaricia a otra mujer.

Mascarada infinita y teatro (lo que remite al mismo título de la colección de relatos, Teatro popular...) en esta libertad de interpretar uno u otro de los papeles sociales, paciente o agente según la terminología transcrita por el padre León ${ }^{61}$. Son éstos los ejercicios prácticos a los que se dedican Solier, Ricardo y Laura en la casa-fortaleza, allí donde la bisexualidad toma caminos físicos o psíquicos según los casos. Se trata sin duda de un discurso barroco que la ciencia paródica del profesor Salt no llega a descifrar.

Después de este episodio carnavalesco las cosas van a encauzarse para adaptarse a ese orden sospechoso del final de la novela. Digamos que todo va a entrar en la normalidad. En ese territorio en el cual las mujeres llevan faldas; en ese mundo en el que los hombres tienen fuerza.

58 P. Herrera Puga, Sociedad y delincuencia..., pp. 253-257.

59 Según la síntesis de Herrera Puga: "Se distinguían porque iban pintados, apuestos, galanes, con los cabellos rizados, los cuellos altos, y se adornaban con toda clase de puntas y copetes" (ibid., p. 257).

${ }^{60}$ Remito a algunas pistas de trabajo y a una bibliografía específica en el artículo de M. Escamilla, “A propos d'un dossier...”, pp. 177-181.

61 "Hacer de paciente", "hacer de agente", "palpar las manos", etc. (cf. P. HerreRa Puga, Sociedad y delincuencia..., p. 258). 
Entretanto, este relato caricaturesco parodia, quizá sin saberlo, unos clichés y unos estereotipos. El vencedor, el héroe, es un ser proteico, un andrógino, aquél que reúne a la vez cualidades femeninas y masculinas y se sirve de ellas para abrirse camino. Lugo y Dávila describe una identidad sexual cambiante y libre, extremadamente provechosa, que es también -no lo dudemos-fuente de placer: placer de los personajes, placer de los lectores...

El disfraz varonil o femenino está muy presente en los mitos y los cuentos. Es a menudo la mujer quien se viste de varón porque eso le permite acceder a una situación superior ${ }^{62}$. En cambio, no hay promoción social cuando es el hombre quien se disfraza de mujer: en efecto, el paso de lo masculino a lo femenino no es una mejora, muy por el contrario. Por eso el disfraz femenino es mucho menos frecuente durante el carnaval, período de risas y de burlas (cf. ibid., p. 78).

La parte central de la novelita de Lugo es, en cierto sentido, una escena de carnaval, lo que remite a las nociones de parodia y libertad. Y es esta libertad lo que otorga a Lugo la posibilidad de hablar sin trabas. Por otro lado, la estética barroca del ser y el parecer abre al autor ricas perspectivas. Lejos de las convenciones sociales, el paréntesis carnavalesco permite a Lugo decir otra cosa, inspirada en los mitos y en las realidades marginales. En este territorio ficticio y posiblemente onírico (después de todo la literatura no es más que un sueño) nuestro autor explora de otra manera las nociones de lo masculino y lo femenino y propone, quizás, otra forma de sexualidad.

En el horizonte de la novela corta española del siglo XVII -ese género literario destinado a un público relativamente amplio- este relato de Lugo sigue la corriente general y se sirve de una serie de clichés y situaciones triviales. Sin embargo, el creador no vacila en profundizar una temática misteriosa, que obsesiona e intriga, para presentarnos una historia cuya significación es más compleja de lo que parece.

FERNANDO COPELLO

Université de Tours/LECEMO

\footnotetext{
62 Cf. François Delpech, "La «doncella guerrera»: chansons, contes, rituels", Formas breves del relato. (Coloquio Casa de Velázquez-Departamento de Literatura Española de la Universidad de Zaragoza. Madrid, febrero de 1985), Madrid, 1986, p. 66; véase, también, la bibliografía ahí citada.
} 